\title{
EFEITO DA LARGURA DO EITO DE DERRUBADA PELO HARVESTER NA OPERAÇÃO DE COLHEITA
}

\author{
Monik Begname de Castro ; Edvaldes José do Amaral ${ }^{2 ;}$ Lucas Rezende Gomide; $^{3}$ \\ Patrícia Andressa de Ávila ${ }^{4}$; Fernanda Buzatti Nascimento ${ }^{5}$ \\ ${ }^{1}$ Mestra em Ciências Florestais / Universidade Federal de Lavras-MG. \\ (monikbc@yahoo.com.br) \\ 2 Engenheiro Mecânico; Celulose Nipo-Brasileira S.A. - CENIBRA \\ ${ }^{3}$ Prof. Dr do Departamento de Ciências Florestais, Universidade Federal de Lavras- \\ MG. \\ ${ }^{4}$ Mestra em Ciências Florestais/Universidade Federal de Lavras-MG. \\ ${ }^{5}$ Engenheira Florestal / Universidade Federal de Lavras - MG
}

Recebido em: 08/04/2017 - Aprovado em: 10/06/2017 - Publicado em: 20/06/2017

DOI: 10.18677/EnciBio_2017A42

\begin{abstract}
RESUMO
O objetivo do trabalho foi avaliar a variação no rendimento em três diferentes larguras do eito de derrubada realizada pelo harvester modelo $1270 \mathrm{E}$, John Deere. Além disso, determinar a disponibilidade mecânica e eficiência de utilização do equipamento e o estudo de tempos e movimento. Foi utilizada a amostragem casual simples em três diferentes situações, relacionando-se as diferentes larguras do eito de derrubada. Foram instaladas parcelas em cada situação e coletados dados do tempo gasto para a máquina processar cada parcela e calculado o rendimento em cada situação, como também disponibilidade mecânica, eficiência de utilização e o estudo de tempos e movimentos, com o objetivo de identificar os elementos do ciclo operacional da máquina. Após a realização desse experimento, foi possível concluir que o processamento de 4 fileiras/linhas não é a melhor opção para o rendimento e sim 3 fileiras/linhas. O equipamento harvester apresentou eficiência de utilização e disponibilidade mecânica satisfatória. Através do estudo de tempos e movimentos, constatou-se que as atividades de processamento e posicionamento do cabeçote foram as que demandaram um maior tempo médio por ciclo operacional.
\end{abstract}

PALAVRAS-CHAVE: Eucalipto, Rendimento, Tempo e Movimento.

\section{EFFECT OF CUTTING STRIP WIDTH BY HARVESTER IN HARVEST OPERATION}

\section{ABSTRACT}

This study aimed to evaluate the yield variation of three different widths of cutting strip by $1270 \mathrm{E}$ harvester, John Deere, as well as to determinate the mechanical availability and utilization efficiency of the equipment, and the study of times and movement. It was used simple random sampling in three different situations, related to different widths of cutting strip. It was allocated experimental plots for each situation and the time data spent for the machine to process each plot was collected. The yield in each situation was calculated as well as the mechanical availability, the utilization efficiency and the times and movement study, aiming to identify the 
elements of the machine's operating cycle. It is possible to conclude that the processing of 3 rows/lines is a better option for the yield than 4 rows/lines. Harvester equipment showed have satisfactory operating yield and mechanical availability. Through the study of time and movement, it was possible to conclude that activities of processing and positioning of cylinder head required a higher average time by operational cycle.

KEYWORDS: Eucalyptus, Yield, Time and Movement.

\section{INTRODUÇÃO}

O setor florestal brasileiro, nas últimas décadas, vem se tornando cada vez mais expressivo e desenvolvido, em que, por meio de muitas pesquisas e investimentos em tecnologia, as empresas brasileiras tornaram-se referência mundial (MORAES, 2012). Dentro desse setor, a colheita é considera uma das atividades mais importantes, porém é a mais dispendiosa em termos de custo de produção. Dentro do ciclo de produção de uma floresta, a colheita é a operação final na qual são obtidos os produtos mais valiosos, sendo um dos fatores que determina a rentabilidade florestal. A colheita florestal representa $50 \%$, ou mais, do total dos custos finais da madeira posta na indústria (BURLA, 2008), e qualquer redução no custo destas atividades é importante, no sentido de aumentar a competitividade das empresas florestais tanto no mercado interno como no externo (BRUMACCI \& SEIXAS, 2002; LISBOA et al., 2014).

A utilização de sistemas mecanizados para colheita de madeira é afetada por diversas variáveis que interferem na capacidade operacional dos equipamentos e, consequentemente, no custo final da madeira (BRUMACCI \& SEIXAS, 2002). No Brasil, existem ainda poucos dados a respeito da real influência dessas variáveis e da capacidade produtiva que se pode esperar das máquinas em determinadas condições de trabalho (BRUMACCI, 2001). Umas dessas variáveis é a largura do eito de derrubada na colheita de eucalipto com sistema harvester.

A largura do eito de trabalho, quando se trabalha em corte raso, ou seja, colhendo todas as árvores do talhão, pode vir a interferir na produtividade em função das características do equipamento como alcance da grua e giro, por exemplo, porém esse problema deve ser minimizado por meio da identificação da largura ideal para cada situação de trabalho e equipamento (BURLA, 2008). Com o aumento da disponibilidade de marcas e consequentemente impacto na concorrência pelo mercado florestal, têm sido encontrados equipamentos com características técnicas superiores de estabilidade, as quais permitem novas análises de layout operacional.

Desta forma, o objetivo do trabalho foi avaliar a variação no rendimento em três diferentes larguras do eito de derrubada (3 linhas, 4 linhas e 5 linhas) realizada pelo harvester modelo 1270E, John Deere. Além disso, determinar a disponibilidade mecânica e eficiência de utilização do equipamento e o estudo de tempos e movimento.

\section{MATERIAL E MÉTODOS}

\section{Caracterização da área de estudo}

Este trabalho foi realizado em áreas de operação de colheita florestal pertencentes à empresa Celulose Nipo-Brasileira S.A., produtora de celulose, em junho de 2013. O projeto foi conduzido em povoamentos florestais comerciais de 
eucalipto, homogêneo e equiâneo em relevo de baixada, na região do Vale do Rio Doce, Minas Gerais, na cidade de Belo Oriente (Figura 1).

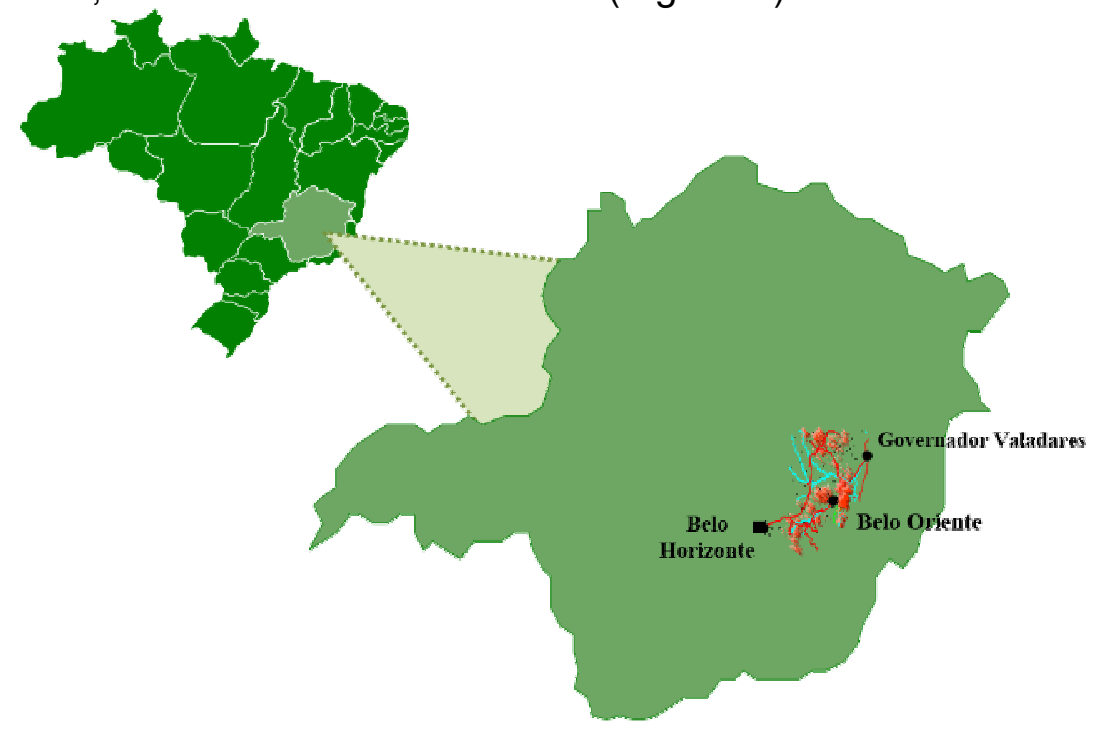

FIGURA 1. Localização da área de estudo.

Fonte: CASTRO, et al., (2017).

As áreas plantadas de florestas são constituídas de variedades de clones híbrido de Eucalyptus grandis com Eucalyptus urophylla, com espaçamento de 3,33 $X$ 3,33 m, sendo o corte final realizado próximo a idade de seis anos. Na região de estudo predomina o solo do tipo cambissolo latossólico.

A região possui clima do tipo Aw, segundo a classificação de Köppen, temperado chuvoso-mesotérmico, com precipitação média anual de $1.163 \mathrm{~mm}$, temperatura média anual de $25,2^{\circ} \mathrm{C}$, média das temperaturas máximas de $31,5^{\circ} \mathrm{C}$, médias das temperaturas mínimas de $19,1^{\circ} \mathrm{C}$ e umidade relativa média de $65,2 \%$ (Carneiro et al., 2003).

\section{Experimento}

Para a condução do experimento, foi utilizado um harvester, marca John Deere, modelo $1270 \mathrm{E}$, tração 6 x 6, equipado com pneus e motor de $170 \mathrm{~kW}$ (228 hp) em regime de 1.900 rpm, com um cabeçote de corte modelo H 270 (Figura 2). 


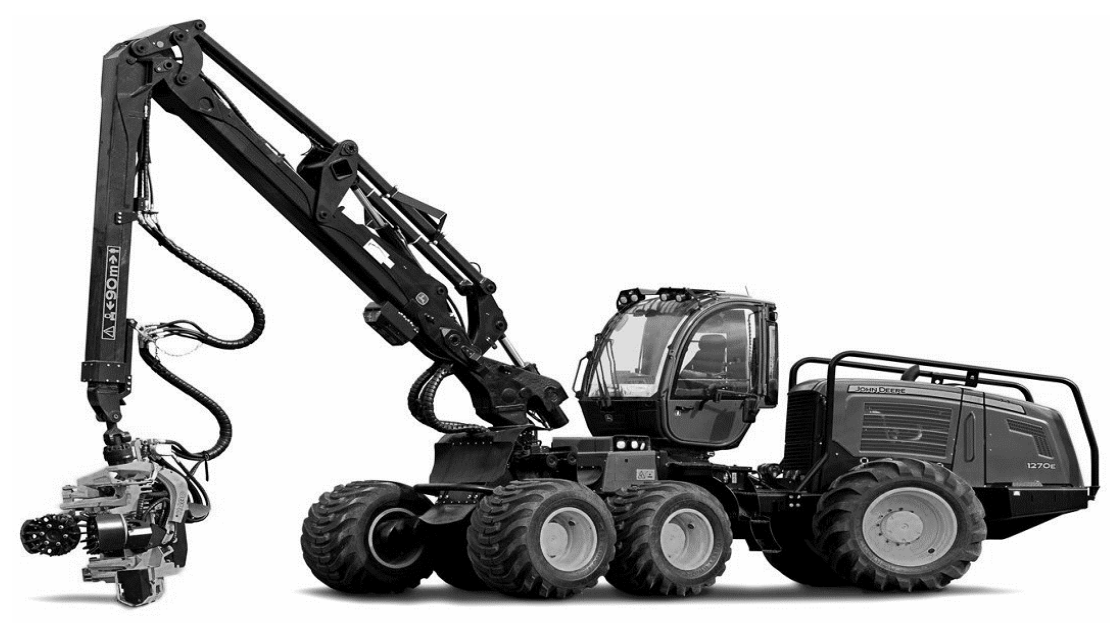

FIGURA 2. Havester John Deere, modelo 1270E.

Fonte: JOHN DEERE, (2013).

O estudo foi planejado para compor três tratamentos de colheita de madeira. Para isso foram demarcadas 10 parcelas por tratamento. No primeiro tratamento, foram demarcadas parcelas compostas por três linhas com 33 árvores, sendo que uma das linhas continha 34 árvores. O segundo tratamento foram parcelas composta por quatro linhas com 25 árvores e o terceiro tratamento cinco linhas com 20 árvores, totalizando 100 indivíduos e $1000 \mathrm{~m}^{2}$ cada parcela de cada tratamento. As parcelas foram demarcadas com o auxílio de uma equipe responsável pelo microplanejamento. Os limites das unidades amostrais foram demarcados para facilitar a visualização dos operadores das máquinas no interior da floresta.

O sistema de corte utilizado foi de toras curtas com casca e as mesmas foram cortadas com 3,00 m de comprimento. Após o corte e a derrubada, foram realizados o desgalhamento, traçamento e destopamento de cada árvore. A derrubada e o processamento das árvores foram realizados à direita da máquina. A madeira, após o processamento, foi depositada à esquerda do sentido de deslocamento da máquina.

A Figura 3 ilustra a máquina deslocando no local de trabalho, sendo que o eito de trabalho foi variando de acordo com cada tratamento. Para cada tratamento foi sugerido um layout de operação (Figura 4). No tratamento 1 (3 fileiras/linhas) o operador posicionava a máquina na $2^{\mathrm{a}}$ linha e capturava as árvores presentes nas respectivas linhas $2^{\underline{a}}, 1^{\underline{a}}$ e $3^{\text {a }}$. No tratamento 2 (4 fileiras/linhas) 0 operador posicionava a máquina na $2^{\mathrm{a}}$ linha e capturando as árvores nas linhas $2^{\underline{a}}, 1^{\underline{a}}, 3^{\underline{a}}$ e $4^{\mathrm{a}}$, respectivamente. E por fim, no 3 tratamento ( 5 fileiras/linhas) operador posicionava a máquina na $3^{\underline{a}}$ linha e capturava as árvores nas linhas $3^{\underline{a}}, 2^{a}, 1^{a}$, $4^{\underline{a}}$ e $5^{\underline{a}}$, respectivamente. 


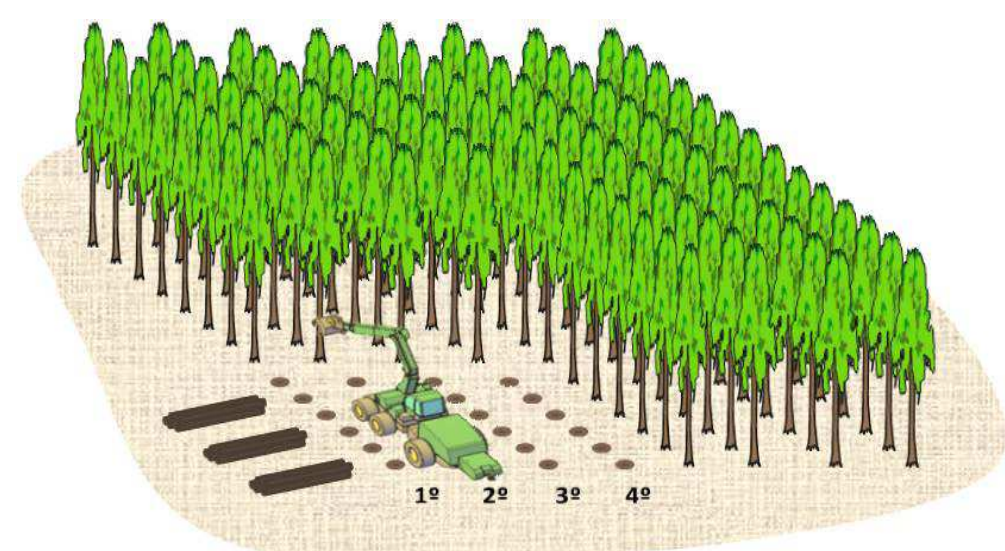

FIGURA 3. Posicionamento do harvester para colheita de eucalipto. Fonte: CASTRO et al., (2017).

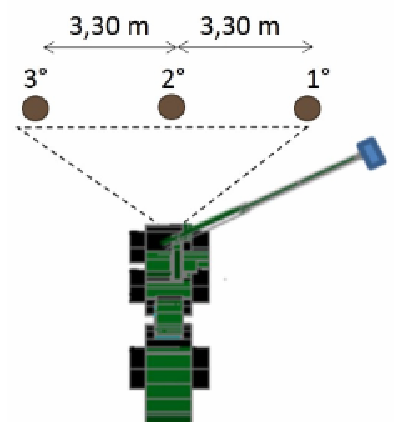

(A)

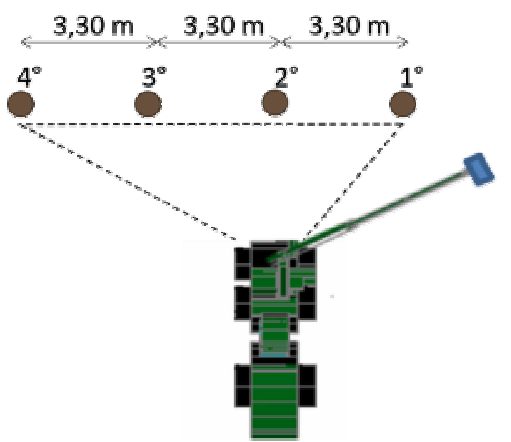

(B)

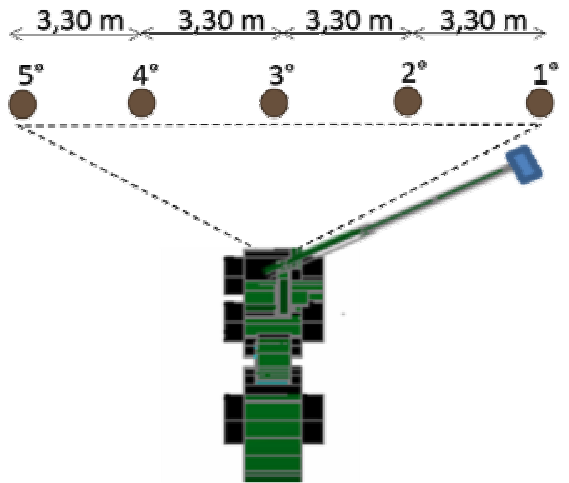

(C)

FIGURA 4. Layout sugerido para a operação em cada tratamento. (A) 3 fileiras/linhas (Tratamento 1); (B) 4 fileiras/linhas (Tratamento 2) e (C) 5 fileiras/linhas (Tratamento 3 ).

Fonte: CASTRO et al., (2017) 


\section{Variáveis avaliadas}

\section{Tempos e movimentos}

Segundo Burla (2008) o estudo de tempos e movimentos tem por finalidade dividir e quantificar o tempo gasto em cada atividade realizada pela colhedora. As observações visuais foram efetuadas a cada 15 segundos durante o trabalho nas parcelas. As atividades foram divididas em deslocamento, posicionamento do cabeçote, corte, derrubada, processamento e outros, descritos a seguir:

a) Deslocamento: considerou-se o deslocamento da máquina na parcela;

b) Posicionamento do cabeçote: todos os movimentos que a máquina realizou com a grua, entre o término do processamento de uma árvore até o posicionamento do cabeçote para a próxima árvore a ser cortada até que as facas e rolos estivessem totalmente fechados;

c) Corte: referiu-se ao tempo de acionamento do sabre até a finalização do corte de derrubada;

d) Derrubada: considerou-se o tempo gasto após o corte até o momento em que a árvore tocasse o solo;

e) Processamento: considerou-se o tempo gasto para que os rolos deslizassem sobre o tronco para efetuar o desgalhamento, traçamento e destopamento até o último torete;

f) Outros: tempo gasto em atividades secundárias não relacionadas diretamente com a produção, como: troca de corrente, ajuste no equipamento, pausa para comunicação via rádio e afins.

\section{Disponibilidade mecânica}

A disponibilidade mecânica (1), segundo Simões et al. (2010), foi definida como o percentual do tempo de trabalho, delineado à máquina mecanicamente apta a desenvolver suas operações, o qual consiste em desconsiderar o tempo gasto para efetuar reparos ou manutenção.

$$
D M=\frac{H-T P M}{H} * 100
$$

Em que:

$\mathrm{DM}=\mathrm{Grau}$ de disponibilidade mecânica (\%);

$\mathrm{H}=$ Tempo produtivo (horas); e

TPM = Tempo de interrupção para efetuar reparos ou manutenção $(h)$.

\section{Eficiência de Utilização}

Considerou-se como eficiência de utilização (2) a porcentagem do tempo verdadeiramente trabalhado em relação ao tempo total planejado para o trabalho.

$$
E U=\frac{H E}{(H E+H P)} * 100
$$

Em que: 
EU = eficiência de utilização (\%);

$\mathrm{HE}=$ tempo de trabalho efetivo $(\mathrm{h})$;

$\mathrm{HP}=$ horas paradas operacionais $(\mathrm{h})$.

\section{Determinação do rendimento}

O rendimento $\left(\mathrm{m}^{3} / \mathrm{h}\right)$ do equipamento foi determinado a partir da fórmula 3 , em que o volume médio por árvore foi disponibilizado pela tabela de inventário pré-corte, multiplicado pelo número de árvores colhidas de cada parcela, obtendo-se o volume extraído por área.

$$
R=\frac{n a \times v a}{h e}
$$

Em que:

$\mathrm{R}=$ Rendimento $\left(\mathrm{m}^{3} / \mathrm{h}\right)$

na $=$ número de árvores colhidas (ud);

$v a=$ volume médio por árvore $\left(\mathrm{m}^{3}\right)$;

$h e=$ horas efetivas de trabalho $(\mathrm{h})$.

\section{Analise estatística do experimento}

Utilizou-se a amostragem casual simples em cada uma das três situações definidas anteriormente, sendo o número de ciclos operacionais estimados através da metodologia utilizada por Barnes (1968). Inicialmente, realizou-se um estudopiloto dos ciclos operacionais, buscando estabelecer o número mínimo de ciclos, para um erro de amostragem admissível fixado em 5\%, a 95\% de probabilidade, através da Equação 4.

$$
n \geq \frac{t^{2} \times C V^{2}}{E^{2}}
$$

Em que:

$n$ = número mínimo de ciclos operacionais necessários;

$t=$ valor de $\mathrm{t}$, Student, no nível de probabilidade desejado e (n-1) graus de liberdade;

$C V=$ coeficiente de variação (\%); e

$E=$ erro admissível (\%).

O Quadro 1 apresenta os experimentos realizados e suas respectivas variáveis resposta.

QUADRO 1. Experimentos realizados e suas respectivas variáveis resposta.

\section{Experimentos}

A

B

C

\section{Variável Resposta}

Tempos e Movimentos

Disponibilidade Mecânica (DM)

Eficiência de utilização (E)

Rendimento (R)

Os dados foram submetidos a análise de variância e as médias foram comparadas pelo teste de Scott-Knott a 5\% de significância. Segundo FERREIRA 
(2000), o teste de Scott-Knott é um teste isento de ambiguidade e seus resultados são claros e objetivos. Os dados foram analisados no programa SISVAR (FERREIRA, 2011). Foi utilizada também análise estatística descritiva, visando complementar a interpretação dos resultados.

\section{Estudo de tempos e movimentos}

\section{RESULTADOS E DISCUSSÃO}

Através do estudo de tempos e movimentos, foi possível determinar o percentual parcial gasto em cada atividade. Com isso foi possível resgatar o tempo gasto em cada etapa do processo, podendo, assim, aperfeiçoá-las e, consequentemente, aumentar a produção do conjunto operador-máquina. Na Figura 5 é apresentada a constituição média das atividades parciais do ciclo operacional do harvester para cada tratamento.

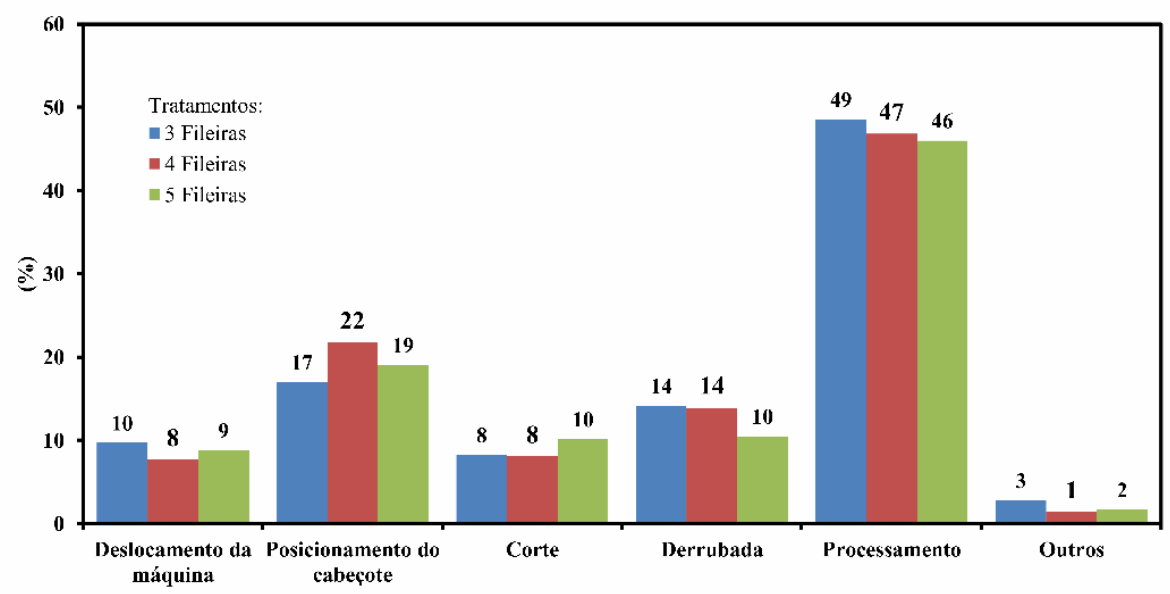

FIGURA 5. Percentual de tempos das atividades parciais do harvester para cada tratamento.

Através do estudo de tempo, constatou-se que as atividades de processamento e posicionamento do cabeçote foram as que demandaram maior tempo médio por ciclo operacional, esse resultado corrobora com os resultados encontrado por LEITE et al., (2014). Esses dados são de suma importância para uma melhor orientação dos operadores, para aumentar o rendimento dos equipamentos, o aumento está diretamente relacionado com a velocidade de giro da corrente e com a qualidade da afiação e corte, além das características naturais da árvore, como a qualidade da desrama natural e a homogeneidade do fuste.

Com relação ao posicionamento do cabeçote, pode-se dizer que a dimensão da circunferência da base das árvores é o principal fator de influência. A experiência e habilidade do operador também podem influenciar o dispêndio de tempo entre uma árvore e outra (BURLA, 2008).

\section{Disponibilidade Mecânica e Eficiência de utilização}

Foi observada uma disponibilidade mecânica média de 96,8\%, que resultou em uma eficiência de utilização média de $87,71 \%$ por hora efetiva de trabalho. CARMO et al., (2012), também encontraram valores próximos a esses. O elevado percentual da disponibilidade mecânica pode ser justificado em função de o harvester avaliado possuir aproximadamente 1.000 horas de uso, ou seja, ser um equipamento relativamente novo. 
A disponibilidade mecânica das máquinas florestais está em torno de $92 \%$, para equipamentos novos, e $85 \%$, para equipamentos com maior tempo de uso (FONTES \& MACHADO, 2014). A eficiência de utilização encontrada pode ser considerada satisfatória, pois segundo MACHADO (2014), a eficiência de utilização de máquinas florestais para a colheita florestal, não deve ser inferior à 70\%.

\section{Determinação do Rendimento}

A Tabela 1 mostra os resultados médios do inventário, porcentagem de sobrevivência, diâmetro médio, altura média, volume da parcela e densidade média de plantio. Dados obtidos durante a coleta.

TABELA 1 Resultado médio do inventário realizado na área experimental.

\begin{tabular}{ccccc}
\hline Sobrevivência & DAP & Altura & Vol. Parcela & Densidade \\
\hline 84,95 & 15,94 & 24,18 & 20,94 & 1000 \\
\hline
\end{tabular}

Considerando o tempo de processamento total das árvores de cada parcela, na Tabela 2 observa-se os valores de média, variância, desvio padrão, coeficiente de variação, erro-padrão para cada tratamento.

TABELA 2. Análise estatística dos tratamentos considerando o tempo total de processamento das árvores de cada parcela.

\begin{tabular}{cccc}
\hline & \multicolumn{3}{c}{ Tratamento } \\
\cline { 2 - 4 } & 3 Fileiras & 4 Fileiras & 5 Fileiras \\
\hline Média & 42,40 & 46,50 & 45,90 \\
Variância & 1,38 & 1,39 & 2,32 \\
Desvio padrão & 1,17 & 1,18 & 1,52 \\
*CV \% & 2,77 & 2,53 & 3,32 \\
Erro-padrão & 0,37 & 0,37 & 0,48 \\
\hline
\end{tabular}

$\left(^{*}\right) \mathrm{CV}(\%)$ : coeficiente de variação;

Segundo PIMENTEL-GOMES (2000), nos experimentos de campo, se o coeficiente de variação for inferior a $10 \%$, diz que o coeficiente de variação é baixo, ou seja, o experimento tem alta precisão. Com isso, conclui-se que a amostragem foi suficiente para obter resultados satisfatórios, garantindo a confiabilidade do experimento.

A Figura 6 mostra os valores do tempo médio de processamento para cada tratamento. As parcelas analisadas apresentaram um volume médio de $20,94 \mathrm{~m}^{3} \mathrm{e}$ cada árvore um volume médio de $0,21 \mathrm{~m}^{3}$. O rendimento médio foi de $29,9 \mathrm{~m}^{3} / \mathrm{h}$, $26,73 \mathrm{~m}^{3} / \mathrm{h}$ e $27,31 \mathrm{~m}^{3} / \mathrm{h}$ de madeira com casca por hora efetiva de trabalho para 3,4 e 5 fileiras, respectivamente.

Comparando os resultados, SIMÕES (2001) e LEITE et al., (2014), encontraram rendimento médio de $31,6 \mathrm{~m}^{3} / \mathrm{h}$. Já BURLA (2008), obteve rendimento médio de $28,50 \mathrm{~m}^{3} / \mathrm{h}$, confirmando os dados encontrados nesse trabalho. Essa diferença de rendimento médio pode ser justificada pela diferença do volume médio das árvores que, BRAMUCCI \& SEIXAS (2002), testando a produtividade de diferentes harvesters, comprovaram que o volume médio das árvores é a variável que melhor explicou $80 \%$ de capacidade produtiva das máquinas. 


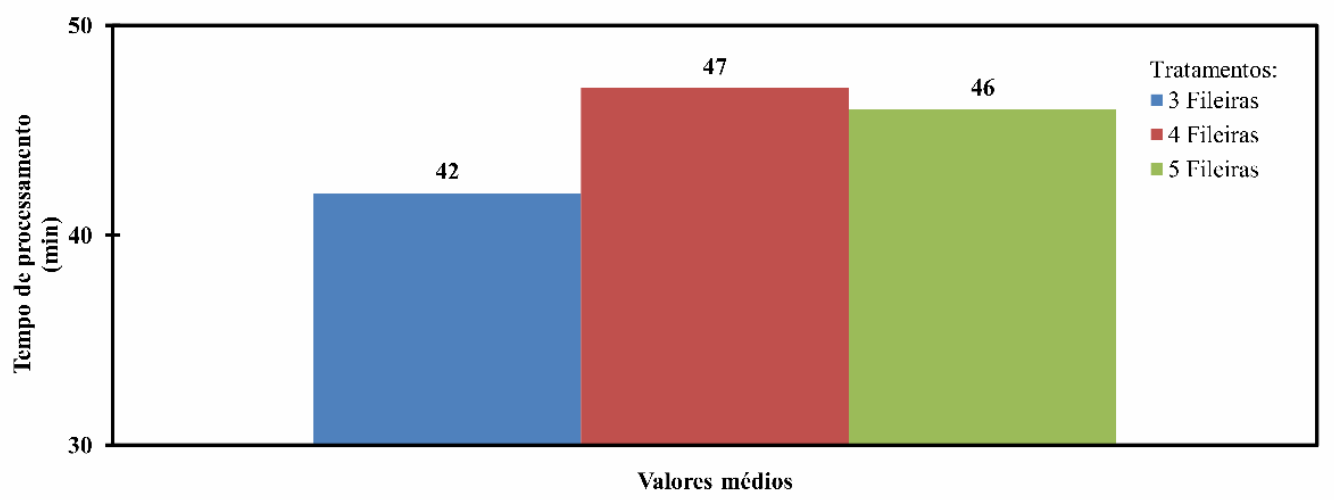

FIGURA 6. Tempo médio de processamento para cada tratamento aplicado.

Como mostra a Figura 6 o tempo médio de processamento para o tratamento 1 (3 fileiras) foi o que apresentou o melhor valor, de 42 minutos, e o melhor rendimento por hora efetiva de trabalho. Na Tabela 3 está demonstrada a análise de variância do harvester empregado no corte e processamento de eucalipto em cada tratamento. Com os resultados experimentais apresentados, pode-se concluir que existe efeito significativo da largura do eito de derrubada pelo havester na operação de colheita $(p<0,0001)$ sobre o tempo de processamento.

TABELA 3. Análise de variância do tempo de processamento para cada tratamento.

\begin{tabular}{lccccc}
\hline Fonte da variação & GL & SQ & MQ & $\mathbf{F}_{\text {observado }}$ & $\mathbf{P r}>\mathbf{F c}$ \\
\hline Entre tratamentos & 2,00 & 87,33 & 43,66 & 20,85 & $0,0000^{*}$ \\
Dentro de tratamentos & 27,00 & 56,53 & 2,09 & & \\
\hline Total & 29,00 & 143,87 & & & \\
\hline
\end{tabular}

$\mathrm{e}^{\star}$ : Teste significativo

A diferença observada em cada tratamento, gerada em função da diferença dos valores médios observados pelos diferentes tratamentos foram submetidos à análise de variância, visando verificar se estas diferenças variam entre si. Ou seja, verificar se entre as diferentes larguras do eito de derrubada do harvester existe uma que seja melhor no rendimento. Assim, concluindo-se que existe diferença significativa entre tratamentos, por meio do teste de $\mathrm{F}$, pode-se então avaliar a magnitude destas diferenças utilizando o teste de média Scott-Knott.

Conforme a Tabela 4 pode-se verificar que existe diferença entre o tempo de processamento em diferentes larguras do eito de derrubada e que o melhor tempo e consequentemente o melhor rendimento foram obtidos no tratamento 1 , eito de derrubada com três linhas.

TABELA 4. Teste de média Scott-Knott para cada tratamento.

\begin{tabular}{cc}
\hline Tratamento & Tempo Médio(min.) \\
\hline 1 & $42,4 \mathrm{a}$ \\
2 & $46,5 \mathrm{~b}$ \\
3 & $45,9 \mathrm{~b}$ \\
\hline
\end{tabular}

Médias seguidas pela mesma letra minúscula não diferem entre si pelo teste de Scott-Knott. 
Apesar do sistema de três linhas ter tido rendimento operacional 9,3\% e 7,0 \% superior ao tratamento 2 e 3 , respectivamente, esse sistema possui algumas desvantagens, quando comparado ao sistema de quatro e cinco linhas. O fato é que com três linhas forma-se grande quantidade de pilhas de madeira processada, com volume de madeira reduzido ao longo do eito de derrubada, com isso o forwarder gastará um maior tempo para recolher essas pilhas.

Uma opção a ser testada é a combinação das três opções de colheita com o uso do forwarder para o estudo de tempos e movimentos. É valido lembrar que o operador não possuía prática em operações com cinco linhas, o que pode resultar em melhores valores, com a prática. Observando a execução do trabalho, percebeuse que o operador seguiu corretamente o layout de operação sugerido para cinco linhas, porém para a operação de quatro linhas, não. $O$ fato de o operador não ter seguido corretamente o layout da operação de quatro linhas, pode ter influenciado o tempo médio de processamento, sendo este ligeiramente inferior ao processo de cinco linhas.

\section{CONCLUSÃO}

Conclui-se que o processamento de 4 fileiras/linhas não é a melhor opção para o rendimento e sim 3 fileiras/linhas. $O$ equipamento harvester apresentou eficiência de utilização satisfatória e superior a 70\%, índice mínimo indicado para máquinas florestais utilizadas na colheita florestal. A disponibilidade mecânica média encontrada foi de $96,8 \%$, valor este adequado para equipamentos relativamente novos. Através do estudo de tempo, constatou-se que as atividades de processamento e posicionamento do cabeçote foram as que demandaram maior tempo médio por ciclo operacional.

\section{RECOMENDAÇÕES}

Sugere-se que a partir dos resultados, que sejam feitos novos estudos de análise de layout de operação, em regiões diferentes da estudada, ou seja, considerando variações na topografia do terreno. Além disso, sugere-se a realização de testes empregando o forwarder em diferentes larguras do eito de derrubada, verificando as mesmas variáveis testadas no presente estudo.

\section{REFERENCIAS}

BARNES, R. M. Motion and time study: design and measurement of work. 6.ed. New York: John Willey \& Sons, 1968.

BRAMUCCI M.; SEIXAS, F. Determinação e quantificação de fatores de influência sobre a produtividade de "harvesters" na colheita florestal. Scientia Forestalis, v. 62 , p. 62-74, 2002. Disponível em: <http://www.ipef.br/publicações /scientia/nr62/cap0 6.pdf>.

BRAMUCCI, M. Determinação e quantificação de fatores de influência sobre a produtividade de "harvesters" na colheita de madeira. 2001. 65 p. Dissertação (Mestrado Recursos Florestais), Escola Superior de Agricultura Luís de Queiros, Piracicaba - SP, 2001.

BURLA E. R. Avaliação técnica e econômica do "harvester" na colheita do eucalipto. 2008. 62 p. Tese (Doutorado em Engenharia Agrícola), Universidade 
Federal de Viçosa, Viçosa - MG, 2008.

CARMO, F. C. A.; SILVA, E. N.; FIEDLER, M. O. P.; MORAES, F. AVALIAÇÃO TÉCNICA DE TRÊS MODELOS DE HARVESTER's. Enciclopédia Biosfera, Goiânia, v.8, n.14, p. 1091-1099, 2012. Disponível em:< http://www.conhecer.org.br/enciclop/2012a/ambientais/avalicao\%20tecnica.pdf>.

CARNEIRO L. C.; RIBEIRO A.; MARTINEZ C. A.; LEITE, F. P. Coeficiente de desacoplamento em plantios jovens de eucalipto. São José dos Campos, SP: Instituto Nacional de Pesquisas Espaciais (INPE), 2003. 6 p. Disponível em: http://mtc-m16b.sid.inpe.br/col/sid.inpe.br/mtcm15@80/2006/11.08.17.09/doc/Careiro Disponível em:< http://www.sbea.org.br/conbea/2014/livro/R0144-3.pdf>.

FERREIRA, D. F. Sisvar: a computer statistical analysis system. Ciência e Agrotecnologia, Lavras, v. 35, n. 6, p. 1039-1042, 2011. Disponível em: $<$ http://www.scielo.br/scielo.php?script=sci_arttext\&pid=S1413-70542011000600001 .Coeficiente.pdf>.

FONTES, J. M.; MACHADO, C. C. Manutenção mecânica. In: MACHADO, Carlos Cardoso. Colheita Florestal. 3 ed. Viçosa - MG: UFV, 2014. 543 p.

JOHN DEERE. Equipamento Florestal da John Deere Disponível em:<http://www.deere.com.br/wps/dcom/pt_BR/industry/forestry/forestry.page?>.

Acesso em: 05 dez. 2013.

LEITE, E. S.; MINETTE, L. J.; FERNANDES, H. C.; SOUZA, A. P.; AMARAL, E.J.; LAERCIO, E. G. Desempenho do harvester na colheita de eucalipto em diferentes espaçamentos e declividades. Árvore, Viçosa, v. 38, n. 1, p. 000-000, fev. 2014. Disponível em: <http://dx.doi.org/10.1590/S0100-67622014000100009>. Acesso em: 07 abr. 2017.

LISBOA, C. F.; MACHADO, T. A.; CUNHA, D. A.; SANTOS, F. L. Avaliação da disponibilidade mecânica, eficiência de utilização e eficiência operacional em um transplantio para para tomate industrial. In: XLIII CONGRESSO BRASILEIRO DE ENGENHARIA AGRÍCOLA, 2014, Campo Grande. Anais...Campo Grande, 2014.

MACHADO, C. C. Colheita Florestal. 3 ed. Viçosa - MG: UFV, 2014. 543 p.

MORAES A. C. Análise do treinamento de operadores de máquinas de colheita de madeira. 2012. 67 p. Dissertação (Mestrado em Ciência Florestal), Universidade Federal de Viçosa, Viçosa, 2012.

PIMENTEL-GOMES, F. Curso de Estatística Experimental. 14. Ed. Piracicaba, SP: Degaspari, 2000. 478 p.

SIMÕES, D.; FENNER, P. T. Influência do relevo na produtividade e custos do harvester. Scientia Forestalis, v.38, n.85, p.107-114, 2010. Disponível em: < http://www.ipef.br/publicacoes/scientia/nr85/cap10.pdf>.

SIMÕES, D.; IAMONTI, I. C.; FENNER, P. T. Avaliação técnica e econômica do corte de eucalipto com feller-buncher em diferentes condições operacionais. Ciência Florestal, Santa Maria, v. 20, n. 4, p. 649-656, out-dez, 2010. Disponível em: 
<https://periodicos.ufsm.br/cienciaflorestal/article/viewFile/2423/1490.DOI:http://dx.do i. org/10.5902/198050982423>. 